\title{
A HISTÓRIA DA DISCIPLINA ESCOLAR CIÊNCIAS NAS DISSERTAÇÕES E TESES BRASILEIRAS NO PERÍODO 1981-1995 ${ }^{1[1]}$
}

\section{THE HISTORY OF SCIENCE AS A SCHOOL SUBJECT IN BRAZILIAN DISSERTATIONS AND THESES FROM 1981 TO 1995}

\author{
Marcia Serra Ferreira ${ }^{2[2]}$ \\ Antonio Flavio Barbosa Moreira ${ }^{3[3]}$
}

\begin{abstract}
Resumo
O artigo aborda a história da disciplina escolar ciências na produção acadêmica brasileira entre 1981 e 1995. Analisa nove dissertações e teses que focalizam o ensino fundamental e que possuem um viés histórico. Com base em Goodson, argumenta que o entendimento do processo de construção social de uma determinada disciplina exige a consideração de fatores internos e externos. Destaca, ao mesmo tempo, a importância de se analisarem, entre os diversos fatores internos, as teses e dissertações defendidas nos programas de pós-graduação. Afirma que ainda há muito a ser investigado sobre a área em pauta, uma vez que boa parte dos trabalhos realizados são muito descritivos. Ou seja, os estudos históricos não têm sido privilegiados nas pesquisas em ensino de ciências. Os trabalhos analisados, apesar de não desconsiderarem a existência de conflitos, acabam por minimizar suas influências no quadro geral de constituição das disciplinas escolares em ciências.
\end{abstract}

Palavras-chave: currículo, ensino de ciências, história das disciplinas.

\begin{abstract}
The article focuses on how science as a school subject has been discussed in Brazilian theses and dissertations between 1981 and 1995. It analyses nine dissertations and theses that investigate elementary school teaching and that adopt a historical approach. Drawing on Goodson's history of the school subjects, the article argues that internal and external factors are necessary to understand the steps followed by a school subject. It stresses the importance of analysing dissertations and theses submitted to Brazilian graduate programmes. It suggests that there is much left to be researched on the development of science as a school subject, since most of the studies carried out are very much descriptive. In other words, historical studies have not been a concern of science education researchers. The studies tend to understress the influence of conflicts on the general context of the constitution of scientific school subjects.
\end{abstract}

Keywords: curriculum, science education, history of school subjects.

\footnotetext{
${ }^{1[1]}$ Esse trabalho é parte do doutoramento realizado desde 1999 na Faculdade de Educação da UFRJ, sob a orientação do professor Dr. Antonio Flavio Barbosa Moreira.

${ }^{2[2]}$ Professora de Didática Especial e Prática de Ensino de Ciências Biológicas e pesquisadora do Núcleo de Estudos de Currículo (NEC) - Faculdade de Educação da UFRJ (http://www.cfch.ufrj.br/nec).

${ }^{3[3]}$ Professor Titular de Currículo e Coordenador do NEC - Faculdade de Educação da UFRJ.
} 


\section{CONTEXTUALIZANDO A TEMÁTICA}

Pretendemos, neste artigo, efetuar uma análise da produção brasileira sobre ensino de ciências, tentando compreender se e como o desenvolvimento histórico desse ensino é abordado nessa produção. Para tanto, recorremos às dissertações e teses defendidas entre 1981 e 1995 que possuem uma abordagem histórica. ${ }^{4[4]}$ O levantamento dos trabalhos foi realizado com base no catálogo de resumos organizado por Megid Neto et al. (1998) e, especialmente, na tese de Lemgruber (1999). Nosso propósito é, reiteramos, entender como esses estudos tratam a história da disciplina escolar ciências e como a inserem no contexto mais amplo das várias pesquisas.

Em nosso estudo, buscamos identificar: (a) modos de abordagem da história da disciplina ciências; (b) relações entre a história e as demais partes dos textos; (c) principais influências teóricas; e (d) metodologias utilizadas na produção desse conhecimento histórico. A análise realizada leva-nos a argumentar que a compreensão dos processos de construção e reconstrução de uma determinada disciplina exige a consideração não só de fatores internos à sua própria comunidade, bem como de fatores sócio-históricos mais amplos. Nesse sentido, sustentamos que ainda há muito a ser investigado sobre a história da disciplina escolar ciências, uma vez que os trabalhos aqui analisados focalizam especialmente os primeiros fatores.

Tanto o trabalho de Lemgruber (1999) quanto nossa análise das dissertações e teses sugerem que os estudos históricos não têm sido privilegiados nas pesquisas em ensino de ciências. Isso se expressa em uma quase ausência de discussões teórico-metodológicas sobre esse tipo de investigação nos textos examinados. Como conseqüência, a história do ensino de ciências assume caráter descritivo e apenas se mostra útil para contextualizar o momento presente. Os fatos e documentos são pouco problematizados e acabam sendo tratados como fotografias, cenas estáticas de uma realidade passada.

Para Foucault (apud Le Goff, 1996), no entanto, a tarefa do historiador não é mais a de decifrar os traços escondidos das várias fontes históricas; na verdade, cabe ao pesquisador a própria seleção e organização de um conjunto de elementos cuja relação não se dá a priori, mas é construída na própria investigação. Isso significa dizer que as fontes históricas não são inócuas, são produtos de contextos sócio-históricos específicos, e devem ser analisadas de modo a desmistificar os seus significados aparentes. Afinal, como afirma Le Goff (1996: 548),

$O$ documento é monumento. Resulta do esforço das sociedades históricas para impor ao futuro - voluntária ou involuntariamente - determinada imagem de si próprias. No limite, não existe um documento-verdade. Todo o documento é mentira. Cabe ao historiador não fazer o papel de ingênuo.

Um outro ponto a ser destacado na pequena produção histórica no que se refere ao ensino de ciências é o pouco diálogo com as teorias e autores do campo do currículo, especialmente com a história das disciplinas escolares. Esse fato pôde ser evidenciado em análise das referências bibliográficas das dissertações e teses examinadas. Como mostraremos

${ }^{4[4]}$ Analisamos os trabalhos de Carvalho (1981), Fracalanza (1993), Gouveia (1992), Junqueira (1988), Krasilchik (1987), Lazzarotto (1995), Machado (1990), Marandino (1994) e Saad (1981). 
posteriormente, o diálogo se dá entre pesquisadores do próprio ensino de ciências, com especial destaque para os trabalhos de Krasilchik (1980 e 1987).

A pouca interlocução com o campo do currículo faz com que os mecanismos de seleção e organização do conhecimento escolar sejam abordados de modo naturalizado, como se as decisões nesse campo tivessem origem apenas nos aspectos relacionados à produção do próprio conhecimento científico. As disciplinas escolares acabam sendo vistas como disciplinas científicas adaptadas para fins de ensino, não se considerando os processos de recontextualização do conhecimento escolar.

De acordo com Santos (1990), a história das disciplinas escolares busca compreender a emergência e a construção das diferentes disciplinas curriculares, investigando tanto a predominância de determinadas tendências quanto as transformações ocorridas nos mecanismos de seleção e organização de conteúdos e métodos de ensino. Entretanto, tais investigações não têm por objetivo apenas a reconstrução sócio-histórica de currículos hegemonicamente posicionados. Na verdade, tais estudos buscam entender as razões e os efeitos sociais tanto das inclusões quanto das exclusões nos currículos escolares, resgatando determinadas posições que perderam as disputas e reconstruindo os processos que acabaram por definir o que é ou não é escolar em um dado momento histórico. Compreendidas deste modo, essas pesquisas podem contribuir para dar visibilidade a narrativas e atores menos conhecidos (Goodson, 1997: 10), desnaturalizando as disciplinas escolares e submetendo-as, então, ao entendimento e à crítica dos profissionais que a elas se dedicam nos vários níveis de ensino.

Além desses objetivos, Goodson (1995) aponta os estudos em história das disciplinas como elucidativos dos mecanismos curriculares de criação e manutenção de padrões socialmente legítimos de estudantes e professores. Segundo esse autor, as formas hegemônicas de conhecimento não são simplesmente mantidas por estruturas macrossociais, mas fazem parte de um sofisticado mecanismo que combina a busca por recursos e status social. No caso específico da Grã-Bretanha, por exemplo, os estudos de Goodson (1995) nos informam que, quanto mais os professores procuraram os incentivos materiais oferecidos pelo Estado, mais o conhecimento profissional se tornou abstrato e descontextualizado. Isso significa dizer que esses profissionais definiram seus currículos em termos eruditos, abstratos e formais - de acordo com objetivos formulados no campo universitário -, o que lhes proporcionou mais recursos e status social.

Santos (1990) aponta que, de modo geral, os estudos em história das disciplinas escolares surgem como uma reação aos trabalhos em sociologia do currículo que interpretam as questões educacionais baseando-se somente nas questões estruturais. Além disso, Goodson (1995) também aponta a predominância de abordagens críticas nos estudos em história da educação produzidos nas décadas de 60 e 70. Para esse autor, o principal valor dos estudos em história das disciplinas escolares está na sua capacidade de investigar a realidade e a autonomia relativa da escolarização. De acordo com Goodson (1995: 120),

A história curricular considera a escola algo mais do que um simples instrumento de cultura da classe dominante. Ela põe a descoberto as tradições e legados dos sistemas burocráticos das escolas, ou seja, fatores que impedem homens e mulheres de criar sua própria história em condições 
de sua própria escolha. Ela analisa as circunstâncias que homens e mulheres conhecem como realidade, e explica como, com o tempo, tais circunstâncias foram negociadas, construídas e reconstruídas.

A construção das disciplinas escolares não se dá, portanto, de modo tranqüilo, mas é fruto de disputas que ocorrem dentro e fora dos sistemas escolares, envolvendo poder, controle, negociações e alianças entre indivíduos e grupos distintos (Cuban apud Santos, 1994). Buscando corroborar tal afirmação, apoiamo-nos em Goodson (1997: 43) para afirmar que as disciplinas escolares são construídas social e politicamente e os atores envolvidos empregam uma gama de recursos ideológicos e materiais à medida que prosseguem as suas missões individuais e coletivas.

Nos países de língua inglesa, Ball (1988), Goodson (1990, 1995, 1996 e 1997) e Popkewitz (1987) têm-se dedicado ao estudo das transformações ocorridas nas várias disciplinas escolares ao longo do tempo, suas emergências e evoluções tanto no nível conceitual como metodológico. No caso das disciplinas Ciências e Biologia, autores como Layton (1973), Rosenthal \& Bybee (1987) e Goodson (1995 e 1997) têm examinado suas trajetórias na Grã-Bretanha e nos EUA, entendendo que essas construções envolveram disputas não apenas acadêmicas, mas também morais e econômicas. As preocupações desses autores residem muito mais na compreensão dos fatores que levam à valorização de determinados conteúdos e métodos em detrimento de outros, do que em reforçar uma verdade ou validade epistemológica dos conteúdos e métodos escolhidos.

Os trabalhos de Goodson que buscam compreender a história de diferentes disciplinas escolares tomam por base o modelo criado por Layton (1973). Nele, freqüentemente, as disciplinas escolares obtêm um lugar no currículo a partir de justificativas como pertinência e utilidade, sendo ministradas por professores não-especialistas. A partir daí, seus mecanismos de consolidação envolvem a emergência e a constituição de uma tradição acadêmica e de um conjunto de especialistas formados nessa tradição (Goodson, 1990). Nesse processo, as disciplinas escolares se afastam de seus objetivos primeiros, passando a ensinar conteúdos abstratos e distantes da realidade e dos interesses dos alunos. De acordo com Goodson (1990), todo esse movimento em direção à abstração e ao academicismo deve ser entendido como uma busca por status, o que possui estreita relação com as disputas por recursos materiais e por um interesse na constituição de uma carreira profissional de maior prestígio. Afinal, as disciplinas não são entidades monolíticas, mas amálgamas mutáveis de subgrupos e tradições (Goodson, 1995).

Compreendendo as disciplinas escolares como estruturas que especificam as condições e os contextos de sentido em que o ensino terá lugar, autores como McKinney e Westbury (apud Goodson, 1996) nos ajudam a pensar para além dos conteúdos, métodos e objetivos de ensino. Na verdade, percebemos que essas estruturas são construídas social e politicamente por comunidades disciplinares que, na busca de recursos e de apoio ideológico, são diretamente influenciadas também por grupos ou facções externas a elas. Como tanto as comunidades disciplinares como os grupos externos não necessariamente compartilham idéias, interesses e objetivos comuns, são gerados conflitos que, segundo Goodson (1996 e 1997), acabam produzindo uma grande estabilidade nos currículos escolares. Assim, torna-se mais 
fácil compreender por que muitas das propostas curriculares construídas a partir de objetivos menos acadêmicos acabam por se estruturar também de modo disciplinar, não se constituindo como alternativas concretas de mudança curricular. Isso se deve, em grande parte, a uma grande estabilidade desse modelo de organização curricular, que foi produzido com base nos vários conflitos que se vêm estabelecendo entre as comunidades disciplinares e os grupos sociais externos a elas.

De acordo com Santos (1990), os fatores que interferem nas mudanças curriculares podem ser classificados em internos e externos. Os fatores internos dizem respeito às condições de trabalho na própria área, tais como: o surgimento de diferentes grupos de liderança intelectual, a criação de centros acadêmicos de prestígio atuando na formação de seus profissionais, a organização de associações profissionais e a política editorial na área. Já os fatores externos estão relacionados à política educacional e aos contextos econômico, social e político mais amplos.

O peso de todos esses fatores depende da tradição da disciplina - prestígio acadêmico e tempo de existência - e do nível de organização de seus profissionais. Tal organização se expressa tanto nas associações acadêmicas quanto nas publicações e política editorial da área. Depende também das condições objetivas do lugar ou país, tais como o seu regime político e a estrutura de seu sistema educacional. Assim, podemos dizer que quanto maior a maturidade de uma disciplina, maior o peso dos fatores internos. Esse peso também aumenta em proporção direta com a descentralização do sistema educacional. Por outro lado, o peso dos fatores externos pode ser mais significativo em países que passam por processos acelerados de transformações.

Goodson (1996 e 1997) nos alerta, por exemplo, para o papel dos sistemas educacionais na produção de padrões socialmente legítimos de professores, alunos, temas e atividades. As comunidades disciplinares se apropriam desses padrões para a construção de retóricas que visam à obtenção de apoio ideológico e de recursos materiais dos grupos externos. Assim, ao mesmo tempo que os sistemas educacionais limitam as comunidades disciplinares - que não são autônomas em suas decisões curriculares e profissionais -, também promovem e sustentam determinadas visões sobre as disciplinas escolares. Quanto maior a capacidade de uma determinada retórica em associar interesses idealistas, materiais e morais, mais estabilizados e naturalizados estarão os discursos e as práticas curriculares.

Buscando compreender os mecanismos de estabilidade e de mudança curriculares em diferentes disciplinas escolares, Goodson (1996 e 1997) defende uma análise que combine elementos das questões internas e externas às comunidades disciplinares. Apesar de não tratar, em seus estudos, de fatores externos muito amplos - como o regime político do país, por exemplo - suas idéias sobre as inter-relações entre os vários fatores são bastante lúcidas. Analisando os processos de estabilidade e de mudanças curriculares, o autor afirma que estas últimas são mais lentas e graduais quando os fatores internos e externos estão em conflito. Uma das causas da estabilidade curricular a que estamos acostumados seria, portanto, a usual falta de harmonia entre tais fatores.

Apoiando-nos em Goodson, defendemos a importância de se associarem fatores internos e externos na construção da história de uma disciplina. Limitamo-nos, contudo, no presente estudo, a focalizar as dissertações e teses defendidas entre 1981 e 1995 em 
programas de pós-graduação brasileiros. Consideramos que essa produção acadêmica constitui um fator interno de grande relevância. Daí nossa preocupação em analisá-la.

\section{INVESTIGANDO A PRODUÇÃO BRASILEIRA}

Conforme já assinalado, as pesquisas no ensino de ciências não têm privilegiado um enfoque histórico. De acordo com Lemgruber (1999), dos 288 resumos de dissertações e teses produzidas na área entre 1981 e 1995, apenas vinte e três abordam a história do ensino de ciências. Para esse autor, a principal característica dessa pequena produção é a de ser de viés, ser uma história de passagem (p. 28), na qual a história é muitas vezes apenas um capítulo, não o objeto central a ser investigado.

Apoiando-nos no estudo de Lemgruber (1999), e visando compreender a história de uma disciplina escolar específica - a disciplina ciências -, optamos também por analisar as dissertações e teses brasileiras defendidas entre 1981 e 1995. Tomando por base a seleção dessa produção já realizada pelo autor, analisamos os resumos e, posteriormente, os textos de seis dissertações de mestrado (Saad, 1981; Carvalho, 1981; Junqueira, 1988; Machado, 1990; Marandino, 1994; Lazzarotto, 1995), duas teses de doutorado (Gouveia, 1992; Fracalanza, 1993) e uma tese de livre docência (Krasilchik, 1987).

A história contada nesses estudos segue, em linhas gerais, três orientações teóricas: os trabalhos de Saad (1981) e Junqueira (1988) estão, em maior ou menor grau, explicitamente filiados às teorias reprodutivistas; Carvalho (1981) utiliza a história da ciência para a compreensão de seu ensino; e, por fim, os demais estudos são mais descritivos e se apoiam nas próprias pesquisas realizadas na área. Desse modo, os trabalhos de Gouveia (1992), Fracalanza et al. (1986) e, principalmente, Krasilchik (1987) são grandes referências para Lazzarotto (1995), Machado (1990) e Marandino (1994).

A principal referência na área são os trabalhos de Myriam Krasilchik (1980 e 1987), autora citada na bibliografia de oito dos nove estudos analisados. Seu texto mais utilizado é a tese de livre docência, publicada no ano seguinte pela editora da Universidade de São Paulo. No primeiro capítulo da obra, Krasilchik (1987) aborda a história das disciplinas Ciências e Biologia entre 1950 e 1985 considerando oito fatores: as situações mundial e brasileira, os objetivos gerais do ensino e as influências teóricas preponderantes, os objetivos do ensino de Ciências, a visão curricular da Ciência, a metodologia recomendada e, por fim, as instituições que influenciaram essas mudanças.

Sua história descritiva segue ordem cronológica e é dividida em décadas. Em cada década, a história do ensino de ciências e biologia assume um caráter evolutivo e linear, como se cada situação ou evento desse origem a outros de modo quase que direto e contínuo. Assim, em uma espécie de reação em cadeia, o contexto mundial influencia a situação brasileira que, por sua vez, atinge a educação e, conseqüentemente, o ensino de Ciências. Por outro lado, embora a autora reconheça que os processos foram contínuos e em alguns casos superpostos, não servindo os limites estabelecidos como marcos nítidos de transição (p. 05), a estrutura de seu texto nos leva a pensar em rupturas entre as várias décadas. É como se a cada período tudo se modificasse, não restando nada das concepções anteriores. Não se trabalha com a possibilidade de diferentes concepções curriculares e pedagógicas co- 
existirem.

O segundo autor que se tornou referência no ensino de ciências foi Hilário Fracalanza. Alguns de seus textos produzidos nos anos oitenta foram citados em cinco dos nove trabalhos realizados, já que a sua tese de doutorado é bem mais recente do que a livre docência de Krasilchik.

Buscando analisar a produção acadêmica e didática sobre o livro didático de ciências no Brasil, a tese de Fracalanza (1993) também aborda a história do ensino de ciências a partir dos anos cinqüenta. $O$ autor argumenta que a situação atual da área é reflexo tanto do nível de propósito - composto por trabalhos acadêmicos e documentos técnico-pedagógicos produzidos por pesquisadores e órgãos governamentais - quanto do nível de fato, ou seja, daquilo que se desenvolve nas escolas. Para ele, o primeiro nível possui relação direta com os movimentos de inovação que ocorreram a partir da década de 50, e sua história acaba por privilegiar as ações mais diretamente relacionadas a formação da comunidade de profissionais ligados ao ensino de ciências.

Os trabalhos de Krasilchik (1987) e Fracalanza (1993) são, de certo modo, complementares, já que tratam do mesmo período, possuem estrutura semelhante e focalizam, principalmente, os aspectos internos à própria comunidade disciplinar. Nesse sentido, as críticas que fazemos à linearidade e ao caráter evolutivo da história construída pela primeira podem ser estendidas ao texto do segundo autor. Assim, embora a história de Fracalanza (1993) coloque maior ênfase no movimento de inovação do ensino de ciências, nos fornecendo importantes indícios sobre como ocorreram os processos de constituição da comunidade da referida disciplina, também não focaliza os conflitos que geraram os discursos e práticas dominantes em cada década estudada.

Apesar das críticas aqui formuladas, defendemos que esses estudos foram marcos de grande significado para as pesquisas no ensino de ciências. Afinal, ambos possuem o mérito de terem sido produzidos por pesquisadores que vivenciaram profundamente todo o período investigado, representantes de uma geração de profissionais que influenciaram de modo marcante os rumos da disciplina escolar ciências no país. Podemos destacar, portanto, o caráter pioneiro dos estudos desses autores. Vale ressaltar, entretanto, que o trabalho que realmente atingiu nacionalmente a área foi o de Krasilchik (1987); a tese de Fracalanza (1993), uma produção mais recente, só foi citada por Lazarotto (1995).

Machado (1990) e Marandino (1994) retomam a história contada por Krasilchik (1987), percorrendo as mesmas décadas em textos com estruturas similares. Apesar disso, as duas não realizam estudos históricos; a história do ensino de ciências serve em ambos os casos para contextualizar o leitor na área em questão. A partir daí, cada autora se dedica ao seu próprio objeto de estudo, inclusive com referenciais teórico-metodológicos distintos.

Machado (1990) realiza seu estudo valendo-se da perspectiva fenomenológica: a história do ensino de ciências é utilizada para compreender o contexto no qual se desenvolve a visão de ciência dos alunos. Segundo a autora, ouvir os alunos significou buscar no seu mundoreal-vivido a Visão de Ciência para a qual eles apontam e, nesse sentido, repensar o Ensino de Ciências nesta direção (p. 04).

Marandino (1994), por sua vez, busca ampliar a história de Krasilchik (1987) por meio de uma síntese das tendências recentes no Ensino de Ciências e suas relações com a perspectiva 
da Didática Crítica (p. 39). Apesar de explicitar que esta história não é fragmentada e que tais períodos se interpenetram (p. 41), seu estudo não atende ao objetivo de ampliação proposto e também permanece muito próximo da história contada por Krasilchik (1987).

O trabalho de Gouveia (1992) é a terceira referência interna à própria área. A autora realiza um pesquisa histórica que aborda a formação continuada dos professores da disciplina escolar ciências no estado de São Paulo. Visando a entender o papel dos cursos de ciências no seu contexto histórico, argumenta que estes não foram suficientes para melhorar a qualidade do ensino, especialmente porque não tomaram como referência o próprio cotidiano escolar. Desse modo, busca na história que constrói os elementos para pensar a formação continuada de maneira mais abrangente e eficaz.

A análise de Gouveia (1992), embora também dividida em décadas, aborda o período de 60 a 90 e insere a história do ensino de ciências em um contexto político, econômico e educacional mais amplo que os trabalhos de Krasilchik (1987) e Fracalanza (1993). Apesar disso, também produz um texto descritivo e linear, não focalizando as disputas que produziram a história da disciplina em questão.

Lazzarotto (1995) trilha o mesmo caminho de Gouveia (1992), sua orientadora e principal referência teórica. A adoção dessa perspectiva se baseia na hipótese de que as conclusões de Gouveia (1992) sobre a formação continuada dos professores de Ciências no Estado de São Paulo são compartilhadas em todo o país, Mato Grosso inclusive, em maior ou menor grau, mais ou menos simultaneamente (p. 25). Assim, analisando as ações da Universidade Federal de Mato Grosso voltadas para os docentes da disciplina ciências entre os anos de 1979 e 1994, Lazzarotto (1995) também procura elementos históricos que permitam propor ações futuras da universidade junto aos professores da rede pública de ensino. Sua história também possui caráter descritivo e segue a linearidade dos textos anteriores. Além disso, do mesmo modo que Gouveia (1992), opta por recorrer ao passado para compreender e modificar a história atual da disciplina escolar ciências.

As pesquisas de Saad (1981) e Junqueira (1988) incluem-se claramente na perspectiva denominada por Goodson (1990) de sociológica, e se destacam por estarem explicitamente filiadas, embora em graus distintos, às teorias da reprodução.

O trabalho de Saad (1981) é o que assume de forma mais contundente o referencial teórico acima mencionado. Assim, narra eventos e circunstâncias que marcaram a evolução do ensino secundário desde as reformas pombalinas até a Lei 5692/71, buscando comprovar a hipótese central de que a disciplina Ciências, do currículo de primeiro grau, serve de veículo para a inculcação da ideologia dominante, visando à reprodução das relações de produção e da estrutura de classes vigente no Brasil (resumo).

Apesar das críticas que faz a uma divisão consensual da história brasileira em períodos balizados por eventos políticos, Saad (1981) não avança na tentativa de compreender a História como um todo (p. 26). Profundamente influenciado pelos teóricos da reprodução, acaba por substituir a divisão política por uma história econômica homogênea, na qual tudo o que é narrado só reforça a tese de que o ensino secundário brasileiro, encaminhando para os cursos superiores e, consequentemente, para as carreiras e profissões de prestígio, não é senão um instrumento de manutenção de status social elevado e de ascensão a este status (Nagle apud Saad, 1981: 55). 
O trabalho de Junqueira (1988) também se enquadra na perspectiva sociológica, percebendo a escola como um espaço de reprodução das estruturas econômico-sociais mais amplas. Ao contrário de Saad (1981), entretanto, a história do ensino de ciências não é o enfoque central de seu estudo. A abordagem do período entre as décadas de 60 e 80 é meramente descritiva e pretende apenas traçar um breve pano de fundo.

A autora defende ser possível relacionar o processo de qualificação diferenciada dos alunos com um processo mais complexo, que é o da reprodução das relações sociais da sociedade brasileira (Junqueira, 1988: 125). Assim, buscando compreender como o conhecimento escolar em ciências é distribuído para alunos de diferentes classes sociais, realiza sua investigação em duas escolas públicas e uma instituição privada, todas atendendo a públicos com condições econômicas e sociais distintas. Suas conclusões apontam para um ensino de ciências que reforça as distinções de classe, preparando melhor aqueles alunos que já se encontram em posição social privilegiada:

Nesse sentido, o ensino de ciências poderia ser categorizado como um dos mediadores no processo de reprodução das relações sociais. Esta mediação seria concretizada através das concepções de ciência e modelos de prática científica difundidos para alunos de classes sociais distintas. (Junqueira, 1988: 125)

A dissertação de Carvalho (1981) também se utiliza da história para compreender o momento presente. Assim, opta por um descrição da evolução do ensino de ciências no sistema formal de ensino, localizando a origem do quadro atual (p. 09). Sua análise, no entanto, embora se centralize nas influências estrangeiras - francesa e, a partir de 1920, americana - sobre a educação e o ensino de ciências, não se utiliza das teorias da reprodução para compreendêlas.

Para o autor, o ensino de ciências é condicionado tanto pela evolução da própria ciência quanto dos sistemas de ensino. Buscando descrever esses dois contextos, defende que na escola atual coexistem concepções anacrônicas e modernas de ciência, cujo conjunto desconexo e internamente inconsistente - transmitido ao aluno, não o instrumentaliza quanto ao uso do modo de pensar científico para a compreensão crítica da realidade e a descoberta de soluções criativas para problemas práticos (Carvalho, 1981: 10).

O trabalho de Carvalho (1981) é o único que possui uma preocupação explícita com os aspectos metodológicos. Nesse sentido, justifica sua opção por um estudo de grande amplitude em detrimento do aprofundamento de um período mais restrito, defendendo que a falta de uma visão abrangente dificulta a interpretação dos resultados parciais, embora importantes e relevantes, e não dá margem à identificação dos elos explicativos ainda em falta (Carvalho, 1981: 06).

O autor argumenta que os estudos históricos não só nos ajudam a explicar o momento atual como nos fornecem pistas para a solução de nossos problemas:

O conhecimento de tais confluências no passado permitirá talvez discernir melhor tais momentos no presente, favorecendo opções potencialmente mais fecundas de resultados futuros. É possível também que algumas causas atuantes no passado, em sentido positivo, cuja atuação não esteja de todo 
extinta, possam ser revitalizadas; e outras, já inativas, possam ser respostas em ação com uma decisão política, com o fim de iniciar um ciclo ascendente no setor de ensino focalizado em nosso trabalho. (Carvalho, 1981: 09)

Embora o trabalho de Carvalho (1981) avance em relação aos demais ao posicionar-se teoricamente frente aos estudos históricos, seu argumento centra-se na idéia de que a relevância desse tipo de pesquisa reside na sua capacidade de explicar o presente e de prever o futuro. Tal afirmação pragmatiza esses estudos e minimiza a importância de compreendermos o passado por ele mesmo, contrariando grandes historiadores como lggers (apud Warde, 1998: 97), para quem a história não é uma ciência que pode fazer afirmações exatas acerca do futuro, porém é uma ciência retrospectiva, que pode e deve intentar explicar o passado para entendêlo.

\section{CONSIDERAÇÕES FINAIS}

Os nove trabalhos analisados constituem importante material sobre a disciplina escolar ciências em nosso país. Isso, entretanto, não esgota o tema, principalmente se modificarmos a visão histórica utilizada, incorporando aspectos teórico-metodológicos tanto da história das disciplinas escolares quanto dos estudos históricos. Tais referenciais nos permitirão elaborar novas questões e analisar as fontes históricas de modo distinto, compreendendo as disciplinas escolares como distintas das ciências de referência e construídas a partir de fatores internos e externos.

De modo geral, podemos identificar uma aparente estabilidade tanto nas análises internalistas de Carvalho (1981) - que toma por base a história da ciência -, Krasilchik (1987), Machado (1990), Gouveia (1992), Fracalanza (1993), Marandino (1994) e Lazzarotto (1995), quanto nas macro-análises de Saad (1981) e Junqueira (1988). Todos esses estudos, apesar de não desconsiderarem a existência de conflitos, acabam por minimizar suas influências no quadro geral de constituição das disciplinas escolares em ciências.

Um exemplo pode ser encontrado na Introdução do livro de Krasilchik (1987: 02), no qual a autora afirma que:

No Brasil, no plano das intenções, aparentemente não ocorre conflito, pois pesquisas na área de educação indicam que cientistas e educadores concordam sobre os grandes objetivos do ensino das Ciências - pensar lógica e criticamente. Embora não haja discordâncias evidentes sobre o papel das disciplinas científicas na educação dos jovens, os resultados estão longe das aspirações compartilhadas por todos que influenciam as decisões curriculares. Tal situação suscita questões para as quais não há resposta fácil: - Por que, na sala de aula, o ensino continua como sempre, e incoerente com as metas aceitas por consenso? - Se o problema não reside na diferença de concepções, qual a explicação para a discrepância entre o que se acredita e 0 que acontece?

Essa idéia de consenso mostra-se bastante problemática, visto que não considera o 
significativo papel dos conflitos entre os vários grupos que constituem a comunidade de profissionais ligados à disciplina ciências. Tais grupos não formam de modo algum uma comunidade homogênea, e os discursos que pensamos serem compartilhados são, na verdade, aqueles que venceram as disputas e se tornaram hegemônicos. A própria autora, ao buscar responder suas questões, problematiza esse consenso, argumentando que pensar lógica e criticamente tem significados diferentes no nível prático (p. 02), que a concordância pode ser só aparente ou mesmo que os professores estão despreparados para tal tarefa (p. 03). Suas dúvidas, no entanto, tendem a desconsiderar as origens históricas de tais conflitos, reduzindo a influência destes àquilo que chama de nível prático. A impressão é que Krasilchik acredita na tradição inventada (Goodson, 1995) dos currículos científicos, não levando em conta os processos históricos que acabam por selecionar e naturalizar certos conteúdos e métodos em detrimento de outros.

Já para autores como Saad (1981) e Junqueira (1988), a estabilidade mantém-se por nossa incapacidade histórica de modificar o quadro econômico e social do país. Os autores, embora reconheçam o currículo como uma construção sócio-histórica, vêem as disciplinas escolares apenas reforçando os interesses dominantes, não existindo brechas de resistência e/ou conflitos em suas histórias. Nesses estudos falta, portanto, um diálogo das macro-análises com os contextos escolares. Afinal, Goodson (1990: 232) nos lembra que essa teorização macro-sociológica é muito diferente de se estudar grupos sociais ativamente em ação em instâncias históricas particulares.

Os trabalhos em história das disciplinas escolares, em especial os de Ivor Goodson (1990, 1995, 1996 e 1997), apontam caminhos distintos daqueles trilhados pelas pesquisas aqui analisadas. Suas conclusões rompem tanto com as perspectivas filosóficas - que naturalizam as decisões curriculares e traçam uma história descritiva e pouco conflituosa quanto com os estudos sociológicos que apenas constatam uma realidade panorâmica, muitas vezes linear e homogênea.

Assim, embora a história do ensino de ciências já tenha sido investigada nas dissertações e teses aqui analisadas, entendemos que os estudos em história das disciplinas podem contribuir de modo decisivo na reconstrução dos rumos das várias disciplinas que abordam as ciências no contexto escolar. A apropriação desse referencial teórico constitui, portanto, um importante passo na compreensão sócio-histórica da disciplina escolar ciências em nosso país.

\section{REFERÊNCIAS}

BALL, S. J. (1988) Relations, structures and conditions in curriculum change: a political history of english teaching 1970-1985. In: GOODSON, I. F. (org.) International Perspectives in Curriculum History. London: Routledge.

CARVALHO, H. G. (1981) Ensino de Ciências no Primeiro Grau: Condicionantes Históricos e Comentário sobre um Livro Texto. Dissertação de Mestrado. Belo Horizonte: UFMG.

FRACALANZA, H.; AMARAL, I. A. e GOUVEIA, M. S. F. (1986) O Ensino de Ciências no Primeiro Grau. São Paulo: Atual.

FRACALANZA, H. (1993) O que Sabemos sobre os Livros Didáticos para o Ensino de Ciências 
no Brasil. Tese de Doutorado. Campinas: UNICAMP.

GOODSON, I. F. (1990) Tornando-se uma matéria acadêmica: padrões de explicação e evolução. Teoria e Educação (2). Porto Alegre: Pannonica.

GOODSON, I. F. (1995) Currículo: Teoria e História. Petrópolis: Vozes.

GOODSON, I. F. \& MARSH, C. J. (1996) Studying School Subjects - a Guide. London: Falmer Press.

GOODSON, I. F. (1997) A Construção Social do Currículo. Lisboa: Educa.

GOUVEIA, M. S. F. (1992) Cursos de ciências para professores do primeiro grau: elementos para uma política de formação continuada. Tese de Doutorado. Campinas: UNICAMP.

JUNQUEIRA, H. (1988) Ensinar Ciências: um Estudo Sociológico do Currículo. Dissertação de Mestrado. Porto Alegre: UFRGS.

KRASILCHIK, M. (1980) Inovação no ensino das ciências. In: GARCIA, W. E. (coord.) Inovação Educacional no Brasil: Problemas e Perspectivas. São Paulo: Cortez e Autores Associados.

KRASILCHIK, M. (1987) O Professor e o Currículo das Ciências. São Paulo: EPU/EDUSP.

LAYTON, D. (1973) Science for the People - the Origins of the School Science Curriculum in England. London: George Allen \& Unwin Ltd.

LAZZAROTTO, A. (1995) As Ações da Universidade Federal de Mato Grosso na Formação Continuada dos Professores do Ensino Fundamental na Área de Ciências: Revisão Histórico-Crítica. Dissertação de Mestrado. Campinas: UNICAMP.

LE GOFF, J. (1996) Documento/monumento. In: LE GOFF, J. História e Memória. Campinas: Editora da UNICAMP.

LEMGRUBER, M. S. (1999) A Educação em Ciências Físicas e Biológicas a partir das Teses e Dissertações (81 a 95): uma História de sua História. Tese de Doutorado. Rio de Janeiro: UFRJ.

MACHADO, O. V. M. (1990) O Ensino de Ciências na Escola de Primeiro Grau: Visão de Ciência Veiculada pelos Alunos. Dissertação de Mestrado. São Paulo: PUC.

MARANDINO, M. (1994) O Ensino de Ciências e a Perspectiva da Didática Crítica. Dissertação de Mestrado. Rio de Janeiro: PUC.

MEGID NETO, J. (coord.) et al. (1998) O Ensino de Ciências no Brasil - Catálogo Analítico de Teses e Dissertações (1972-1995). Campinas: UNICAMP/FE/CEDOC.

POPKEWITZ, T. (1987) The Formation of School Subjects: the Struggle for Creating an American Institution. London: Falmer Press.

ROSENTHAL, D. \& BYBEE, R. (1987) Emergency of the Biology Curriculum: a Science of Life or a Science of Living? In: POPKEWITZ, T. The Formation of School Subjects: the Struggle for Creating an American Institution. London: Falmer Press.

SAAD, A. A. (1981) Ciência e Ideologia na Escola de Primeiro Grau: o Ensino de Ciências Físicas e Biológicas em Goiás. Dissertação de Mestrado. Rio de Janeiro: IESAE/FGV.

SANTOS, L. L. C. P. (1990) História das disciplinas escolares: perspectivas de análise. Teoria e Educação (2). Porto Alegre: Pannonica.

SANTOS, L. L. C. P. (1994) História das disciplinas escolares: outras perspectivas de análise. VII Encontro Nacional de Didática e Prática de Ensino - Anais: Conferências, Mesas Redondas e Simpósios. Goiânia: UFMT. 
WARDE, M. J. Questões teóricas e de método: a história da educação nos marcos de uma história das disciplinas. In: SAVIANI, D.; LOMBARDI, J. C. e SANFELICE, J. L. (orgs.) História e História da Educação: O Debate Metodológico Atual. Campinas: Autores Associados/HISTEDBR, 1998.

\section{CORRESPONDÊNCIA}

Núcleo de Estudos de Currículo (NEC). Faculdade de Educação da UFRJ. Avenida Pasteur, 250 fundos - sala A-110. Praia Vermelha. CEP: 22290-240. Correio eletrônico: mserra@ufri.br e afmcju@infolink.com.br 